\title{
Shifting Language Paradigm: An Integration of Five Dimensions of Culture in Teaching English as a Foreign Language in Pakistan
}

\author{
Hassan Bin Zubair ${ }^{1}$, Abrar Hussain Qureshi ${ }^{2}$, Adnan Tahir $^{3}$ \& Athar Munir ${ }^{4}$ \\ ${ }^{1}$ Department of English, National University of Modern Languages, Islamabad, Pakistan \\ ${ }^{2}$ Department of English, University of Lahore Pakpattan Campus, Pakpattan \\ ${ }^{3}$ Riphah University, Faisalabad, Pakistan \\ ${ }^{4}$ Govt. Emerson College, Multan, Pakistan \\ Correspondence: Hassan Bin Zubair, Department of English, National University of Modern Languages, \\ Islamabad, Pakistan. E-mail: hbz77@yahoo.com
}

\author{
Received: April 4, 2018 Accepted: April 28, 2018 Online Published: May 5, 2018 \\ doi:10.5539/ijel.v8n5p53 URL: https://doi.org/10.5539/ijel.v8n5p53
}

\begin{abstract}
This study explores the inseparable entities of language and culture. Mastering the cultural element is crucial in the EFL/ESL language learning process. Furthermore, the study investigates the role of culture in the EFL/ESL curriculum since the 1980s. The paper examines the integration of culture into the ESL/ EFL classrooms in Pakistan. Most Pakistani EFL classrooms continue to simply focus on the grammar-translation approach, where students have to memorize significant and non-significant grammar points and then do dozens of exercises drilling the newly learned grammatical form(s). The foundation for teaching culture language learning include the $5 \mathrm{Cs}$, the Five Dimensions of Culture, language learning authentic materials, and the Cultural Experiential Learning Cycle. Through experiencing role-playing situations and distinguishing similarities and differences between cultures, students are culturally prepared with appropriate behaviors and responses when they encounter a similar situation in the target culture. The recommendations provided should enable Pakistani educators and administrators to effectively integrate culture into EFL curricula. This Paper explores the incorporation of culture in the context of Pakistani language learning environments. It also investigates strategies and techniques that make the language learning process productive, so that Pakistani educators can incorporate them within their classrooms.
\end{abstract}

Keywords: foreign language, culture, Pakistani, learning, English, American, ELF classrooms

\section{Introduction}

Conventional Pakistani EFL (English Foreign Language) classrooms employ a grammar-translation approach, in which students are required to memorize significant and non-significant grammar points in the target language. Students are reluctant to speak up and natural classroom interaction is kept to a minimum. Further hampering these students is a lack of familiarity with the target host culture that inhibits their efforts at blending in and, often results in misunderstanding the behaviors and life-style of the target culture. This lack of awareness regarding appropriate social conduct results in an inability to effectively navigate in their new environment. Not surprisingly, these factors often result in reduced motivation to further improve and expand English language skills. In some cases, the continued frustration and negative experiences can even give rise to an aversion for the target culture. These problems are grounded in the failure to teach cultural communication skills in the classroom. More specifically, this paper addresses one of the key reasons why Pakistani students have difficulties in their interactions in English-speaking host countries. More specifically, awareness of and sensitivity to American culture is not a part of the English language curriculum in Pakistan. At best, any relevant cultural instruction provided in Pakistan is based on the instructor's idiosyncratic experiences. The lack of an intercultural competence curriculum leads, at best, to poor English communication skills or, at worst, to aversion to learning English altogether. This, of course, presents challenges for Pakistani students wishing to enter the workforce and severely limits their ability to enter colleges in the U.S. or other English speaking countries. This paper provides strategies and techniques for teaching culture in EFL classrooms. These tools will help bridge students' gaps in learning classroom. English and real world English in a natural way and increase their motivation and confidence 
to "live in and communicate in" an English speaking environment. The literature review also demonstrates the need for even more research and study on the teaching of English to Pakistani students through American culture. In contrast with, Poland, Germany and even China, for example, Pakistan's distance from the U.S. and other English-speaking countries does not afford many Pakistani students the opportunity to easily go abroad and naturally interact with the inhabitants of the host countries to improve their English skills. The English language proficiency level is so poor, in fact, that Pakistani students have difficulties both in passing final exams to simply graduate from high school and passing college entrance exams in Pakistan. Many students who would like to get their university degree in the U.S. fail entrance exams, such as the TOEFL, when they apply to American colleges. Ultimately, their failure is not due to students' ability, work ethic or desire to learn English, but rather in the methodology and curriculum used to teach English, namely, the grammar-translation approach.

In this era of globalization, English language is the international language of choice. All international organizations require the acquisition of English skills in order to communicate for purposes of trade, diplomacy, science and the like. English is not only important on the international stage; it is also the default secondary language within Pakistan, as Pakistan has a multitude of citizens of non-Pakistani heritage. One of the most highly prized skills, and in some cases a requirement, for businesses in Pakistan is at least a basic level of English language literacy. Many beginning positions in Pakistan require a job interview conducted in English. These are often accompanied by job applications which are written and filled out in English. Therefore, it is imperative that effective language programs be developed and implemented in Pakistan. Such programs will allow Pakistani students to successfully pass high school and college exams, increase student enrollments in U.S. colleges, and reduce learners' frustration and increase comfort while interacting with the target culture. Acquiring English skills will also help the Pakistani people to be more successful in world trade and allow for a higher standard of living. Fundamentally, teaching a foreign language is incomplete without the study of the related culture. The clear and unique relationship between a culture and its language is based on the work of educators from various disciplines. The assumption is that there is a unique and clear relationship between a culture and its language. This paper addresses the ever-increasing emphasis on a culture language approach and the ways in which it is being implemented. It will show that in the last few decades the integration of culture and language acquisition has come to the foreground. Educational programs have often still failed to grasp the usefulness of this approach. Even where flexibility is permitted, many teachers are unclear as to how to incorporate culture in EFL/ESL classrooms. As a result, they make little or no effort to include culture as part of the EFL/ESL curriculum. This uncertainty may very well be one of the leading reasons why language teaching is still ineffective in Pakistan. The major concept explored is the subject of how culture can be applied in Pakistani educational environments to make the language learning process more effective. Scholars believe that teaching a foreign/second language might be functionally inaccurate and incomplete without the study of the related culture. Many tools discussed in this paper concentrate on developing students' cultural awareness in EFL/ESL classrooms. Role-playing is identified as an effective teaching technique in language and culture teaching. Using the effective instructional sequence (EIS), it describes how role-playing can be implemented in the teaching of the target language in secondary schools in Pakistan to increase students' cultural and language awareness. Toward the end of the paper, conclusions based on the research are discussed. Finally, recommendations given for improving Pakistani language learning instructions are presented. These recommendations encompass the techniques and strategies discussed throughout the study and are targeted toward students, teachers, and the school administration. This holistic approach strengthens and underpins the goal of effective foreign language instruction for the Pakistani educational system.

\section{Delimitations of the Study}

This research examines the incorporation of culture in Pakistani EFL classrooms. A great deal of the pertinent and applicable literature was written and available only in Pakistani. It would have been optimal had this research been translated into English and made available in the United States. However, this is not the case. Therefore, the first limitation of the study is that the necessary Pakistani students have not been translated into English and is not available in libraries, either in print or digitally. While the general topic of cultural incorporation in ESL/EFL classrooms is well documented, there is very little literature available that specifically relates to the inclusion of culture in Pakistani EFL curricula. Despite this limitation, enough research has been conducted on the topic in general to extrapolate a knowledge base that applies to the Pakistani classroom. The findings and recommendations reflect research and literature reviews from both English and Pakistani sources. Additional research should be conducted, especially within the Pakistani educational system, before the specific recommendations are implemented. However, the principles and general recommendations provided should offer Pakistani educators a strong foundation from which to start the process of cultural incorporation. 


\section{Ideals for Foreign Language Learning}

"The Standards for Foreign Language Learning: Preparing in the 21st Century" (ACTFL, 1996) are based on three broad assumptions, each of which has clarifying points:

"1). Competence in more than one language and culture enables students to:

- Interact with people from other cultures

- Better understand what is happening in cultures other than their own

- Appreciate their native culture and language on a deeper level

- Read, watch, and interact with knowledge sources from the target culture

- Relate to the global community in a more meaningful way.

2). Any students can successfully learn a language and its corresponding culture. To succeed, they:

- Must be able to acquire the language and culture as a part of their entire school experience.

- Realize the benefits of gaining and maintaining proficiency in the foreign language

- Learn the language in multiple ways and in different settings

- Acquire proficiency at varied rates.

3). Foreign language curricula need to reflect language and culture simultaneously. As a result, it:

- Has direct correlation to programs that include productive tools, techniques, testing, and technology.

- Shows ever improving standards at all levels of the educational system.

- Develops and improves upon communication and thinking skills.

Given these assumptions, the Standards focus on outcomes of foreign language learning:

- Students' ability to communicate in authentic settings

- Understanding the target culture contextually

- Making connections to knowledge through the target language, competency in recognizing how languages and cultures compare

- Participation in multilingual communities." (Shrum \& Glisan, 2009, p. 55 )

When students study a language, their use of the 5 C's might be weighted more toward one or the other, depending on individual goals which range anywhere from finding a rewarding career to simply fulfilling graduation requirements. The Standards provide flexible guidance to teachers, educators, and others who are involved in students' educational lives. This guidance consists of curricular elements that should be "woven" into the $5 \mathrm{C}$ 's goal areas. These elements are language systems, "cultural traits and concepts, communication strategies, critical thinking skills, and learning strategies" (Shrum \& Glisan, 2009, p. 55).

\section{Research Questions}

1) How are culture and language learning related? What role does culture play in foreign language acquisition?

2) To what extent has "culture" been incorporated into methodologies for language teaching?

3) What does current research reveal about the effectiveness to teach English in Pakistani secondary schools using the grammar-translation approach?

4) What does current research reveal about effective ways to incorporate culture to enhance language acquisition in EFL/ESL classrooms?

\section{Research Methodology}

This research is qualitative in nature. Specific theoretical framework and research methodology has been selected keeping in mind both the main aspects of culture and foreign language learning process. This multiple theoretical framework helps this research positively and takes to the target oriented findings. Authors, such as Byram (1989), Brown (2007), Peck (1998), Atkinson (1999), Moran (2001), and Mishan (2005) have discussed culture as an important and necessary component in an effective language curriculum. Moran subsequently added that cultural awareness helps students discover and explore their personal perspectives, not only on the target culture but the world as a whole (Moran, 2001, p. 75). Whatever the motivation and reasons, learning a foreign language is always "culture bounded" (Valdes, 1986). The flip side of the coin is that the features of a 
target culture cannot be deeply taught without integrating instruction in the target culture's language. "Using authentic sources from the target language community, newspapers, films, photos, news broadcasts, and television shows make language learning more realistic, comprehensive, and often enjoyable. According to Nunan and Miller, authentic materials "are not created or edited expressly for language learners" (Nunan \& Miller, 1995, p. 68). In the process, the learners develop personal perspectives toward cultures. Along with a better understanding and respect for the diversity of cultures, students also gain a level of appreciation for their own native culture (Moran, 2001, p. 78). Through exposure to authentic products, utilization of genuine language, and culturally specific topics, students are able to avoid stereotypes and gain an appreciation for different facets of the target culture diamond. Students develop empathy and cultural sensitivity toward both the target culture and their native culture, and a healthy respect for the differences in the cultures. Authentic materials help students perceive the target language and culture from a more realistic perspective. This imparts a level of comfort and ease with the unique cultural idiosyncrasies of the target culture. Learning the meanings of behaviors and specific communication styles for different situations, students are better able to communicate appropriately in different situations and avoid cultural misunderstandings. This increased level of proficiency improves motivation and, promotes the desire to continue to improve. Linguistic competence defines a student's lexical, phonological, morphological, and syntactic knowledge of a language. It is the ability to construct words from morphemes, phrases and sentences from words, and appropriate utterances from sentences. It is important to note that, linguistic competence plays a lesser role in teaching foreign languages in many countries, in contrast to other types of communicative competence (Gilmore, 2007, pp. 24-27). Pragma linguistic competence refers to a student's ability to understand and communicate appropriately using phrases or colloquialisms typically used by target culture speakers. In general, they are used when responding to speech acts such as requests, refusals, compliments, or apologies. Contextualization is an important aspect of pragma linguistics as it helps the learner know when and how to use the target language (Gilmore, 2007, pp. 28-32). Socio-pragmatic competence is the ability to discern what is socially or culturally appropriate in the target culture. It entails an understanding of social conventions and taboos unique to the target culture, "what is appropriate to say to whom, and in what situations" (Peterson \& Coltrane, 2003, p. 2). The use and development of strategic competence will allow students to build confidence in their target language skills and will help keep them engaged. Additionally, when students commit errors in L2 speech this communicative strategy will help them work through and negotiate the meaning instead of giving up on the conversation completely (Gilmore, 2007, pp. 40-44). Finally, discourse competence refers to students' ability to create cohesive discourse in different genres of spoken or written speech such as in personal letters, narratives, gossip, or jokes.

"When speaking, the student's ability to produce coherent and cohesive discourse depends on a number of factors such as determining when it is his/her turn to speak, staying on topic, making appropriate transitions to new topics, providing short responses to the speaker, and how the end the conversation" (Gilmore, 2007, pp. 44-46).

\section{Analysis and Discussion}

The main goal of a language teacher is to develop intercultural competence. Additionally, the concept of incorporating culture as a necessary and effective teaching strategy is examined and justified. Attention is given to the tools, strategies, and techniques for incorporating culture in the EFL classroom based on students' needs and standards. Many authors, such as Brown (2007), Moran (2001), Nababan (1974), Tang (1999), Kramsch (2001), and Wardhaugh (2011) have explicitly stated that language and culture are closely related. Wardhaugh (2011) stated that "the nature of the relationship between language and culture has fascinated, and continues to fascinate people from a wide a variety of backgrounds" (Wardhaugh, 2011, p. 229). Similarly, Nababan (1974) concluded that "it is impossible to learn the culture well without learning the language of the target context because beliefs, feelings, perspectives, and so forth are functionally embedded and interwoven within the language" (Nababan, 1974, pp. 18-30). As such, even a fluent speaker might misunderstand the messages he/she hears or reads or sees without sufficient cultural skills. Tang (1999) went even further, by asserting that "language is culture." For Tang, absent the threshold ability to think in the target language, the speaker will not be sufficiently fluent in that language and culture. Perhaps mystically, Tang (1999) opined that language is the soul of the country. More in line with the mainstream, Brown, similarly postulated that "language is a part of a culture, and culture is a part of the language; the two are intricately interwoven so that one cannot separate the two without losing the significance of either language or culture" (Brown, 2007, p. 164).

"The relationship between language and culture in the context of EFL/ESL has been widely discussed. However, the fruits of these discussions were not put into practice in the EFL/ESL curriculum of the 1960s." (Sysoyev \& Donelson, 2002). 
Rather than thoroughly adopting the Culture-Language approach, "instructors continued to use other approaches such as the Classical approach, the Grammar-Translation approach, the Direct approach, the Audio-lingual approach, Suggestopedia, Total Physical Response, and the Silent Way" (Brown, 1995, pp. 16-17). These methods emphasized structure and vocabulary and neglected cultural aspects of communication. Beginning in 1970, the cultural teaching of language was clearly in ascendance in EFL/ESL. Initially, those adopting this approach did so in a rudimentary fashion using only dialogues (Brown, 2001, pp. 34-37). However, as the positive results of the Culture-Language approach were increasingly recognized as:

"It was realized that to communicate effectively, one should adapt the properties of his language use (such as intonation, lexical choice, and syntax) to the social "variables" ... in which he interacts with others. Consequently, [the] role of culture in the ESL/EFL curriculum grew." (Purba, 2011, p. 46)

"The growing importance of culture in the EFL/ESL curriculum was evidenced in the 1980s by the appearance of syllabi designed to assist teachers using the Culture-Language approach" (Rivers, 1982; Robinson, 2001). Two of the most important scholars of that period, Byram (1989) and Zarate (1986), articulated "the expanding understanding of culture teaching to include using various sources of information, identifying stereotypes and other representations, contextualizing information, explaining one's own culture to foreigners and establishing personal contacts with foreigners and preparing trips to a target language country" (Risager, 2007, p. 86). Additionally, the concept of incorporating culture as a necessary and effective teaching strategy is examined and justified. Attention is given to the tools, strategies, and techniques for incorporating culture in the EFL classroom based on students' needs and standards. Teaching culture in EFL classrooms helps students to observe culture not only from a familiar perspective - often with a corresponding stereotypical perception - but from new perspectives as well.

"During language instruction, it is important to combine topics from different disciplines with authentic materials that represent components of and variations within the target culture. By doing so, the teacher allows students to acquire cultural information from different perspectives, thereby mitigating cultural stereotypes that often develop when a culture is explored through a one-sided prism" (Hammerly, 1982).

When creating lessons plans, teachers should follow "The Standards for Foreign Language Learning: Preparing for the 21st Century" published by the "American Council on the Teaching of Foreign Language" (1996). All of these goals reflect the purposes for learning foreign languages. It looks through the goals, the $5 \mathrm{C}$ 's, to clarify their important role in learning foreign language (ACTFL, 1996, p. 3).

\section{(i) Group/Pair Work Activities}

The focus of the first goal, Communication, is written and verbal communication between peers. Students grasp words and phrases for interactions with each other. For instance, students can exchange information about different events by asking each other questions (ACTFL, 1996, p. 4). Students also develop listening and reading skills in order to comprehend content; for example, the main idea of a text they have just read (ACTFL, 1996, p. 4). As an example, students can engage in a role-playing activity to present ideas on the following: what are you going to do after finishing high school? "Communication activities are very important since they contribute to the development of students' proficiency in the language by focusing on meaningful speaking skills" (Zwiers, 2008, pp. 148-150). In the second goal, Culture, students understand culture through its practices, that is, "what to do, when, and where" (Shrum \& Glisan, 2009, p. 55). This goal reflects cultural practices that are produced by their distinctive views, attitudes, and perspectives of the target culture's society. For instance, teachers can present American gestures by demonstrating the gestures, explaining their meaning, and explaining when and where these gestures are used (Shrum \& Glisan, 2009, p. 55). Students understand culture through its products, the artifacts created by native speakers of the culture, including documents, religion, clothing, etc. (Moran, 2001, p. 48). Students focus on cultural products and their reflection of cultural perspectives. These products can be tangible or intangible. Tangible products are perceptible through the five senses: sight, smell, touch, taste, and hearing (ACTFL, 1996, p. 4). Examples of tangible products would be objects or places. Intangible products are those that aren't perceived through the five senses, most often ideas or concepts such as a system of education. These cultural products are produced by distinctive views, attitudes, beliefs, and perspectives of the culture's society. Teachers can present cultural products by showing pictures or by demonstrating them. For example, when creating a lesson plan about food in America, a teacher can include commonplace cultural products such as common American foods, sandwiches, hamburgers, and pies, which inherently reflect perspectives of the culture.

The third goal, Connections, focuses on learning the language itself and on other subject areas where students are able to acquire skills from other fields of knowledge including cultural competence and awareness. A teacher can connect each English class with other disciplines such as art, history, culinary, and literature. Connections also 
focus on a broader examination and subsequent extraction from the various cultural information sources to which students have access. It's a "new window of the world" (ACTFL, 1996, p. 4). Students gain proficiency in the foreign language because they are able to seek necessary information and then analyze the content. For example, students can observe distinctive viewpoints on different ways of traveling in the U.S. Connection activities help students to acquire knowledge not only in language and cultural context, but also to be proficient in other disciplines. Grammatical forms are good examples of how students compare their own language to what they are learning in the target language. The goal demonstrates the students' knowledge of the cultures they're learning. In this way, students are able to further develop their own assumptions about cultural systems in general. Comparisons activities can be very helpful in terms of both developing target culture skills and basic concepts of critical thinking. The fifth goal, Communities, centers on the student's practical application of learned knowledge beyond the school setting. The skills and knowledge gained from foreign language instruction allow students to enjoy the many artistic endeavors of the target culture such as books, movies, music, and more, all while continuing to improve their language and cultural skills. All of these goals guide students toward proficient interactions with others. The goals are meant to be taken holistically, not presented separately, with equal emphasis placed on each. "Each goal area contains two or three standards that describe the knowledge and ability that all students should acquire by the end of the program or high school education in order to achieve the goals" (Shrum \& Glisan, 2009, p. 52). A teacher should also provide students with tasks that connect with other disciplines for better understanding of the cultural context. Furthermore, teachers should eliminate artificial characters or texts when trying to provide perspectives of the culture. Finally, a teacher should expect and accept divergent student responses (Shrum \& Glisan, 2009, p. 64).

\section{(ii) EFL Text Books}

A significant theme throughout this paper is the inclusion of cultural awareness that facilitates and promotes learning of the target language. Beyond language acquisition, other benefits accrue from exposure to the target culture. The opportunity to compare cultural values and perspectives increases students' awareness of both cultures. In this section, resources that can be used to develop fundamental knowledge of a target culture are explored more fully. These resources can include films, songs, texts, newspapers articles, and even advertisements from the target culture. Currently, however, English Foreign Language (EFL) teachers largely rely only on textbooks when teaching classes.

"There is a broad range of international and local versions of current EFL textbooks. These often include additional components such as student books, workbooks, teacher's editions, CDs, DVDs, and test books. International, sometimes referred to as global, textbooks are produced for universal use. These international materials can be used in any country, whereas local textbooks are designed to satisfy the national curriculums of the country in which it was produced" (Pulverness, 1995, pp. 7-11).

Skopinskaya's review of textbooks designed for the general global market revealed them to be, not surprisingly, universal in nature. They were insufficient in regards to individual learner's needs and presented only the most basic of language or cultural features that would be considered acceptable or useful anywhere in the world. In an interesting contradistinction, Skopinskaya's review of local textbooks found that "they attempt to teach EFL utilizing aspects of the learners' natives' culture instead of the target cultures" (Skopinskaya, 2003, pp. 43-45).

\section{(iii) EFL Indigenous Cultural Resources}

Mishan identifies seven separate categories of cultural products that, when produced by those who speak the language of the target culture natively, are genuine. "They are Literature, Broadcast Media, Newspapers, Advertising, Song and Music, Film, and Information and Communication Technology" (Mishan, 2005, p. 95). During the exploration and comprehension of different genres of Literature, students practice their reading skills and become more competent with the target culture's culture and language.

"Through Literature, students are able to observe and explore the target culture from native speakers perspectives. They gain a better understanding of essential features of the target culture, such as historical information, social interactions, and authentic vocabulary." (Mishan, 2005, pp. 97-112)

Broadcast Media involves cultural products such as radio and television. It has many genres and examples include: news, art reviews, and entertainment programs. Broadcast Media is a convenient tool that allows students to quickly observe how target cultural values have changed over time. Newspapers provide students with a broad range of topics ranging from local news to entertainment. This allows students to choose topics grounded in their own personal interests (Mishan, 2005, p. 154). "Students are exposed to cultural microcosm[s] that allow them to experience different nuances of the target language as a result of the wide range of writing styles represented" (Mishan, 2005, p. 163) The different topics that are succinctly represented in Newspapers 
help students to more quickly compare their varying features. Advertising demonstrates what is available and preferred by customers in the target culture. It captures what they buy - food, clothing, furniture, housing, entertainment etc. In other words, it reflects the lifestyle of the target culture. "Advertisements can be serious, funny, exciting, enigmatic, sexy and so on, but, with the notable exception of health and safety campaigns (such as those intended to discourage drink-driving), they are rarely unpleasant" (Mishan, 2005, p. 184). Songs and Music reflect peoples' attitudes toward different things such as life, love, the world, and so forth. The primary feature students derive from the melody, rhythm, and content of Songs and Music is the cultural spirit of the target culture. Through historic Songs and Music, students can track the target culture's historical events such as wars, revolutions and famines, and get a feel for a people's spirit during those times. Songs and Music allow students to observe how the target culture celebrates their holidays and might allow a student to be able to gauge the relative importance and meanings of the various celebrations to the people of that culture (Mishan, 2005, pp. 196-197).

"Film is a great resource for observing such non-verbal communication as gestures, body movements, and behaviors" (Mishan, 2005, p. 225). "One of the fundamentals to remember when using films for language learning, is that a film can be enjoyed and understood even without language, as the films of the silent era demonstrated" (Mishan, 2005, p. 224). Through watching the target culture's movies, students will be able to respond to questions such as "What do people eat and drink, where, and with whom? How do people spend their free time? Where do they shop? What do they wear?" (Mishan, 2005, p. 226). Moreover, "students will be exposed to jargon, regional dialects, accents, idioms, and informal verbal and non-verbal language" (Mishan, 2005, p. 225). Students may be able to visit any place in the target culture using ICT. Communication through email has many advantages. One advantage of using email as a communication medium is that it circumvents any predisposition of social class, accents, or race, and allows students to communicate in a more neutral environment emphasizing similarities between cultures (Mishan, 2005, p. 254). "Each partner should benefit equally from the relationship, by providing models of the native language's cultural information and corrective feedback" (Mishan, 2005, pp. 250-251). In conclusion, each of the five cultural dimensions described by Moran (2001) should be explored in EFL classrooms. Learners need to be able to recognize and understand the five cultural dimensions in order to both respect the target culture and appropriately communicate within the target culture's context. The cumulative teaching and awareness of the five dimensions of culture is an important and even essential stage in language learning and cross-cultural communication.

\section{(iv) Concepts of Role Playing}

It also examines role-playing as an effective teaching technique in the foreign language classroom. It also explores how role-playing can be used in EFL/ESL classrooms in order to enhance students' cultural and linguistic awareness. The paper suggests an effective sequence for integrating role-playing in language learning instruction to increase students' language proficiency. "The term "role" derives from "rolled-up" scripts which actors used two thousand years ago in Ancient Greece" (Maheshwari, 2011). "Role-playing is a way of bringing situations from real life into the classroom" (Doff, 2007, p. 232). According to Ladousse, role-playing allows students to represent and experience a character known or familiar in everyday life from the perspective of an individual in the target language culture (Ladousse, 2003, p. 23). In Scenarios, Discourse, and Real-Life Roles, as "a set of norms and expectations applied to the incumbent of a particular position" (Munby, 1978, p. 68, as cited in Di Pietro, 1987, p. 227). However, Al-Arishi (1994) identified two distinct types of role-playing. In the first, role-playing is defined as "real play."

"Role-playing as a classroom activity fits in with this desire for realism since it gives students the chance to rehearse the typical activities they will presumably perform in real life: greetings, making suggestions, asking for directions, ordering food in a restaurant, or functioning at bank, post-office, airport, etc." (Al-Arishi, 1994, p. 339)

In role-playing, students act out the situation as if it is really happening. Di Pietro's second category of role-playing is "surreal-playing." "While real playing seeks a willing acceptance of the belief that the classroom can become the real world," surreal-playing is "willing suspension of disbelief on the part of students that the role-play situation is one of pretense" (Al-Arishi, 1994, p. 341). The proponents of surreal role-playing note that students love to imagine. People of all ages, especially children, often spend time imagining themselves as someone else or in different situations when they are at play. By engaging in surreal role-playing, the teacher is utilizing something that comes naturally as a learning tool (Al-Arishi, 1994, pp. 340-341).

\section{(v) Structure and Social Functions}

In the book Techniques and Resources in Teaching Grammar, Celce-Murcia stated that "these techniques 
facilitate a match between structure and social functions, and can be used for both communicative and focused grammar practice" (Celce-Murcia, 1988, p. 61). During role-play, students have the opportunity to practice using vocabulary words and phrases (both new and previously learned) as well as apply new grammatical forms in a natural way. Hence, the subject is more naturally memorized and learned. By stressing creative communicative work, role-playing helps avoid repetitive exercises which can become rote and boring. Role-playing helps students to build confidence in communicating with each other as well as in using the target language (Larsen-Freeman, 2011, pp. 127-129). Thus, role-playing enhances social skills and prepares learners for real-life communication. As EFL is intended to be a practical and focused curriculum, role-playing activities should start with a focus on the daily life of peers in the target language country. Role-playing situations that involve relationships with family and friends, leisure time activities, and traditions or customs allow students to fundamentally relate to the target culture (Moran, 2001, pp. 59-64). In this way, students can more easily assimilate the language because it centers on situations and experiences in their personal lives. At this stage, some students may not fully comprehend the teacher's explanations and may need additional time to absorb new material. Role-playing takes this learning curve into account as the entire process gives students additional time to comprehend the material fully (Kodotchikova, 2002). In this way, role-playing helps to level out the learning curve of the class by allowing students more time to correct themselves. Further, role-playing activities offer good listening practice. In order to make the conversation meaningful, students must inherently learn to listen to and understand their classmates all the while interacting and performing their own role.

\section{Findings}

The sequence of the cultural experiential learning cycle can provide students with accurate information of "a particular kind of culture learning," where a teacher assumes different roles in order to help students acquire cultural awareness based on their own preferences. While the "cultural experience" is generally efficacious, experience has demonstrated that, absent appropriate countermeasures, a number of students emerge from the "cultural experience" with psychological blocks or "cultural fatigue" vis-à-vis the target culture. However, Kodotchikova (2002), Doff (2007), Larsen-Freeman (2000) and other educators have shown that teachers can help most, if not all, students avoid psychological "blocks/cultural fatigue" with role-playing. "As language and culture are interrelated, language cannot be taught without culture, but there are many ways of co-teaching language and culture. One is role-play" (Kodotchikova, 2002). All told, the incorporation of role-playing can be a very effective teaching method for purposes of acquiring, improving, and maintaining overall intercultural communication skills in a foreign language. Role-playing establishes a cultural context for the language learning process, by giving students an opportunity to experience communicating in the new language. This experience engenders a sense of social confidence when interacting in the target culture. In addition to being more culturally aware, students will have learned the language in a more natural way and approach the idea of L2 communication with increased self-esteem and confidence. To reiterate, students can successfully acquire and use a second language only when its cultural context is incorporated with language learning. The inclusion of role-playing into the learning process solidifies contextual understanding of the culture and improves overall language acquisition.

Using techniques such as role-playing, the quality and efficacy of foreign language education for students can increase greatly. Role-playing is an especially effective teaching technique for several reasons. First, students interact with each other in designing the scenario and subsequently performing it; they improve their speaking, communicative, grammar, and listening skills. Second, students learn about cultural issues by identifying similarities between target and native cultures. Third, through experience with different social situations, students develop personal perspectives toward target cultures as well as the world as a whole. Fourth, roleplaying activities prepare students for real life. Role-playing activities also are available for different proficiency levels and age groups. A comfortable and non-threatening atmosphere in the class is required for role-playing to be most effective. The right environment allows students the freedom to make mistakes and feel empathy toward classmates. This increases motivation, builds trust, overcomes shyness, and helps students to have fun. In addition, to make role-playing effective, a teacher needs to go through each step of the sequence designing a lesson plan. The creation and incorporation of effective role-playing in the SLA classroom requires both effort and desire on the part of the teacher and the students. Adherence to the principles, techniques, and concepts highlighted will enable teachers to achieve their objectives.

\section{Conclusion}

These teaching tools, techniques, and strategies make language teaching effective. The tools, techniques, and strategies discussed in this paper are all integral to a successful and effective language program. Most Pakistani students spend years receiving instruction in the English language. However, despite all their efforts, they meet 
with little success, often only acquiring the most rudimentary command of the English language. Incorporation of culture into English classes in Pakistan is essential for improving efficacy. This will allow students to communicate appropriately based on the situation and allow students to adapt to their target cultures more easily. We are living in a time of rapid globalization where nations are becoming increasingly more diverse, multilingual, and multicultural. As the world becomes smaller and smaller, people need to communicate across borders more effectively, not only in order to understand each other but also to achieve success in international business ventures. It is particularly important that language educators, and the educational systems they are a part of, realize that it is their responsibility not only to teach the language itself, but also the culture it is inextricably linked to. This approach not only increases understanding between multicultural and multilingual people in different communities, but also improves international relations on the world level. Therefore, EFL teachers in Pakistan and other countries must ensure that there is space in their curricula to incorporate cultural diversity and awareness when learning a foreign language.

\section{Recommendations}

Culture language educators define culture through interrelated dimensions that include products, behaviors, ideas, beliefs, perspectives, communities, persons, and so forth. In other words, culture reflects unique insights into a country that can be different from other countries. Acquiring an understanding of the target culture inevitably reduces cultural miscommunications and misunderstandings between people from different cultures. This process inherently needs to start within the classroom setting. If adopted in Pakistani EFL classrooms, these strategies would improve development of students' overall language ability. "The Standards for Foreign Language Learning include the $5 \mathrm{C}$ 's goal areas: communications, cultures, connections, comparisons, and communities" (ACTFL, 1996, p. 1). This framework is used by most teachers in the United States and serves as a basis for teaching world languages. This is accomplished utilizing authentic materials such as cultural artifacts, literature, multimedia, and music. The research also suggests that incorporating role-playing is an effective teaching technique in foreign/second language instruction. According to the research, through role-playing, students display cultural nuances of the target culture and demonstrate cultural communication that can be different from their native cultures. By acting out real-life situations, students increase self-awareness and integrate into the target culture more appropriately.

The following recommendations are offered to educational leaders, teachers, and students:

1). Administrators and School officials should:

- Encourage, support, and facilitate the use of appropriate technologies that teachers and students can leverage during instruction.

- Support and facilitate continuing education for administrators and teachers to stay abreast of teaching methodologies and techniques for language instruction.

2). Teachers and Instructors should:

- Develop lesson plans that address the Five C's, the Five Dimensions of Culture, and the Experiential Learning Cycle. This will provide students with the framework needed to not only respect the target culture, but to embrace and understand it more deeply.

- Roleplaying helps students avoid psychological blocks during communication with native speakers.

3). Students should:

- Remain open to learning about other cultures and actively compare what they learn with their native culture.

- Seek out authentic materials from the target culture and engage in open discussion with the teacher and other students.

\section{References}

Al-Arishi, A. Y. (1994). Role-play, real-play, and surreal-play in the ESOL classroom. ELT Journal, 48(4), 337-346. https://doi.org/10.1093/elt/48.4.337

American Council on the Teaching of Foreign Languages (ACTFL). (1999). Standards for foreign language learning in the 21 st century.

American Council on the Teaching of Foreign Languages (ACTFL). (1996). Standards for foreign language learning: Preparing for the 21st century. Yonkers, NY: Author.

Brown, J. D. (1995). The elements of language curriculum (1st ed.). Boston, MA: Heinle \& Heinle Publishers. 
Brown, H. D. (2001). Learning a second culture. In J. Merrill (Ed.), Culture bound: Bridging the cultural gap in language teaching (pp. 33-48). Cambridge, UK: Cambridge University Press.

Brown, H. D. (2007). Principles of language learning and teaching (5th ed.). East Lansing, MI: Longman Publishing.

Celce-Murcia, M. (1988). Techniques and resources in teaching grammar. Los Angeles, CA: Oxford University Press.

Di Pietro, R. J. (1987). Strategic interaction: Learning languages through scenarios. Cambridge, England: Cambridge University Press.

Hammerly, H. (1982). Synpaper in language teaching (1st ed.). Blaine, WA: Second Language Publications.

Kodotchikova, M. A. (2002). Role play in teaching culture: Six quick steps for classroom implementation.

Ladousse, G. P. (2003). Role Play (16th ed., Vol. 19, p. 5). New York, NY: Oxford University Press.

Larsen-Freeman, D. (2011). Techniques and principles in language teaching (3rd ed.). New York, NY: Oxford University Press.

Mishan, F. (2005). Designing authenticity into language learning materials. Portland, OR: Intellect Books.

Moran, P. R. (2001). Teaching culture: Perspectives in practice. Boston, MA: Heinle Cengage Learning.

Nabanan, P. W. J (1974). Language, culture and language teaching. RELC Journal, 5(2), 18-30. https://doi.org/10.1177/003368827400500203

Pulverness, A. (1995). Cultural studies, British studies and EFL. Modern English Teacher, 4(2), 7-11.

Purba, H. (2011). The Importance of including culture in EFL teaching. Journal of English Teaching, 1(1), $44-56$.

Risager, K. (2007). Language and culture pedagogy. From a national to a transnation alparadigm. Clevedon, England: Multilingual Matters Ltd.

Rivers, W. (1982). Teaching foreign language skills (2nd ed.). Chicago, IL: University of Chicago Press.

Robinson, P. (2001). Task complexity, task difficulty, and task production: Exploring interactions in a componential framework. Applied Linguistics, 22, 27-57. https://doi.org/10.1093/applin/22.1.27

Shrum, J. L., \& Glisan, E. (2009). Teacher's handbook (4th ed.). Boston, MA: Heinle Cengage Learning.

Skopinskaja, L. (2003). The role of culture in foreign language teaching materials: An evaluation from an intercultural communicative competence in language teacher education. In I. Lázár (Ed.), Incorporating intercultural communicative competence in language teacher education (pp. 39-57). Strasbourg, France: European Centre for Modern Languages/ Council of Europe Publishing.

Sysoev, P. V., \& Donelson, L. R. (2002). Teaching cultural identity through modern language: Discourse as a market of an individual's cultural identity.

Wardhaugh, R. (2011). An introduction to sociolinguistics (6th ed.). Malden, MA: Basil Blackwell Ltd.

Zwiers, J. (2008). Building academic language (1st ed.). San Francisco, CA: Jossey-Bass.

\section{Copyrights}

Copyright for this article is retained by the author(s), with first publication rights granted to the journal.

This is an open-access article distributed under the terms and conditions of the Creative Commons Attribution license (http://creativecommons.org/licenses/by/4.0/). 